\title{
Flyer Velocity Characteristics of the Laser-Driven Miniflyer System
}

Federal Manufacturing \& Technologies

T. D. Rupp;

R. J. Gehr;

R. W. Harper; and

D. B. Stahl, Los Alamos National Laboratory;

S. A. Sheffield, Los Alamos National Laboratory; and

D. L. Robbins, Los Alamos National Laboratory

\section{KCP-613-6209}

Published July 1999

Approved for public release; distribution is unlimited.

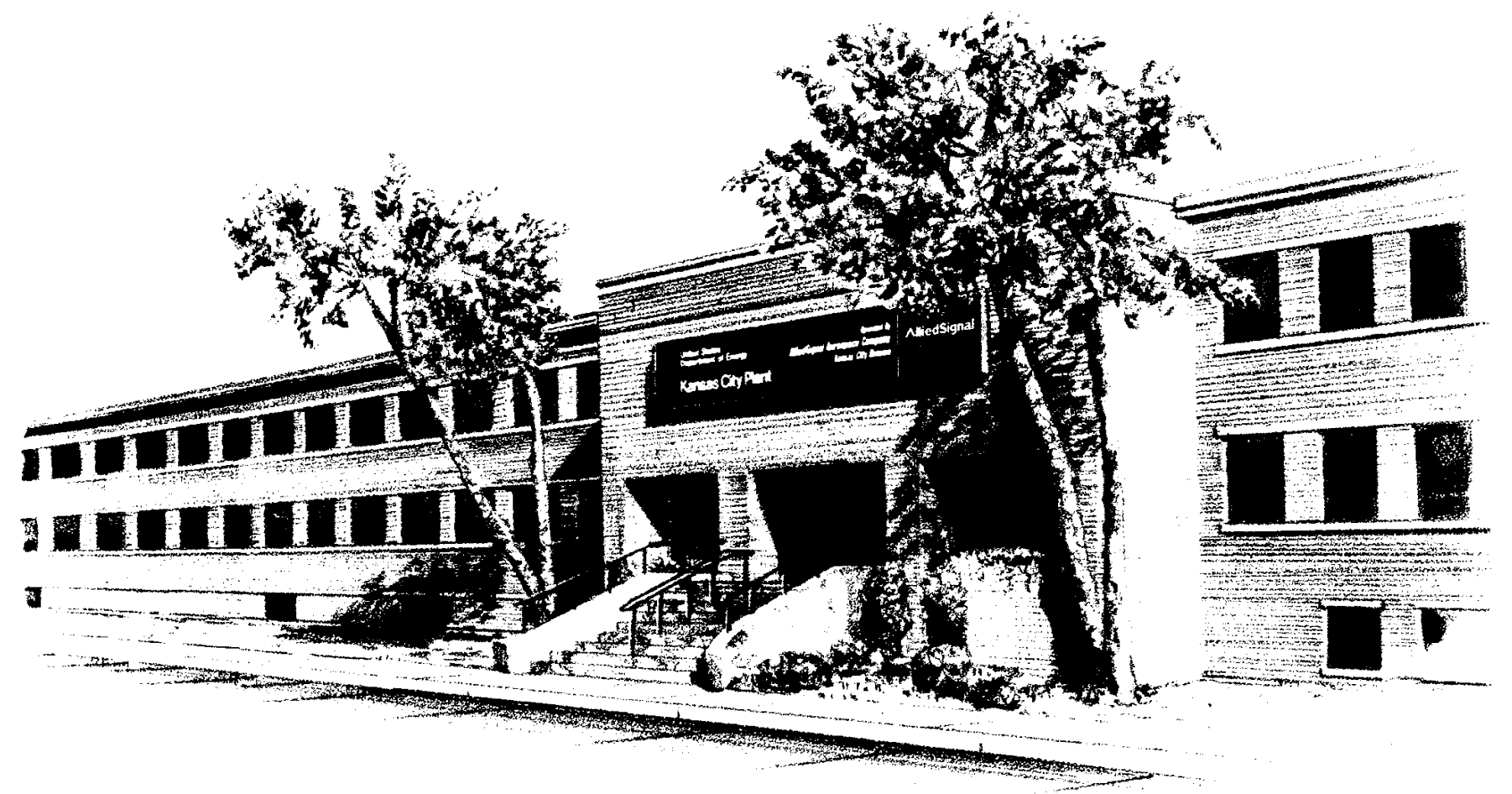




\section{DISCLAIMER}

This report was prepared as an account of work sponsored by an agency of the United States Government. Neither the United States Government nor any agency thereof, nor any of their employees, makes any warranty, express or implied, or assumes any legal liability or responsibility for the accuracy, completeness, or usefulness of any information, apparatus, product, or process disclosed, or represents that its use would not infringe privately owned rights. Reference herein to any specific commercial product, process, or service by trade names, trademark, manufacturer, or otherwise, does not necessarily constitute or imply its endorsement, recommendation, or favoring by the United States Government or any agency thereof. The views and opinions of authors expressed herein do not necessarily state or reflect those of the United States Government or any agency thereof.

Printed in the United States of America.

This report has been reproduced from the best available copy.

Available to DOE and DOE contractors from the Office of Scientific and Technical Information, P. O. Box 62, Oak Ridge, Tennessee 37831; prices available from (423) 576-8401, FTS 626-8401.

Available to the public from the National Technical Information Service, U. S. Department of Commerce, 5285 Port Royal Rd., Springfield, Virginia 22161, (703) 487-4650.

Copyright ( 1999 by AlliedSignal Inc. The Government is granted for itself and others acting on its behalf a paid-up, nonexclusive, irrevocable worldwide license in this data to reproduce, prepare derivative works, and perform publicly and display publicly. 
KCP-613-6209

Distribution Category UC-706

Approved for public release; distribution is unlimited.

\section{FLYER VELOCITY CHARACTERISTICS \\ OF THE LASER-DRIVEN MINIFLYER SYSTEM}

T. D. Rupp;

R. J. Gehr;

R. W. Harper; and

D. B. Stahl, Los Alamos National Laboratory;

S. A. Sheffield, Los Alamos National Laboratory; and

D. L. Robbins, Los Alamos National Laboratory

Published July 1999

Paper submitted to American Physical Society

June 28, 1999

Snowbird, Utah 


\title{
FLYER VELOCITY CHARACTERISTICS OF THE LASER-DRIVEN MINIFLYER SYSTEM
}

\author{
David B. Stahl ${ }^{1}$, Russell J. Gehr ${ }^{2}$, Ron W. Harper ${ }^{2}$, Ted D. Rupp ${ }^{2}$, Steven. A. \\ Sheffield $^{1}$, David L. Robbins ${ }^{1}$ \\ ${ }^{1}$ Dynamic Experimentation Division, Los Alamos National Laboratory, Los Alamos, NM 87545 \\ ${ }^{2}$ AlliedSignal FM\&T/NM, Los Alamos NM 87544
}

\begin{abstract}
The laser-driven MiniFlyer system is used to launch a small, thin flyer plate for impact on a target. Consequently, it is an indirect drive technique that de-couples the shock from the laser beam profile. The flyer velocity can be controlled by adjustment of the laser energy. The upper limits on the flyer velocity involve the ability of the substrate window to transmit the laser light without absorbing, reflecting, etc.; i.e., a maximum amount of laser energy is directly converted into kinetic energy of the flyer plate. We have investigated the use of sapphire, quartz, and BK-7 glass as substrate windows. In the past, a particular type of sapphire has been used for nearly all MiniFlyer experiments. Results of this study in terms of the performance of these window materials, based on flyer velocity, are discussed.
\end{abstract}

\section{INTRODUCTION}

Pulsed lasers have been used extensively to generate short duration shock waves, including investigations of spall[1,2], detonation of explosives[3], high pressure generation[4], and thin film/coating bond strength measurements[5]. Laser generated shock techniques offer several advantages, including low cost, high shot throughput, and simplified experimental apparatuses. However, these are countered by the requirement for thin samples, complicated laser generated plasma physics and heightened resolution requirements for experimental diagnostics.

In this work, a laser is used to launch a $0.05 \mathrm{~mm}$ by $3.0-\mathrm{mm}$ diameter copper flyer plate to terminal velocities up to $0.65 \mathrm{~km} / \mathrm{s}$. Flyer plates are attached to substrate windows with several microns of adsorbed material sandwiched between for absorption, buffering, and insulation. Unlike direct laser-generated shock techniques, laser-launched plates detach plate launch from plate impact. Therefore, the shock generated in the target is decoupled from laser deposition and buffered from discontinuities in the laser beam profile.
The MiniFlyer has been used to determine spall strengths of target materials and to generate Hugoniot data when coupled with velocity interferometry[6,7]. Our goal is to improve conversion of the laser energy into kinetic energy of the flyer plates (achieve higher flyer plate velocities), to maintain flat flyer plates (for one-dimensional impact) and to understand any change of state of the flyer plate prior to impact. We report the laser energy/flyer velocity relationship as a function of substrate material (launching window material). We also include effects which the various window materials have on flyer plate acceleration and ring.

\section{EXPERIMENT}

Flyer plates are launched with a single shot $\mathrm{Nd}$ :Glass laser that produces a pulse of $\sim 20 \mathrm{~ns}$ (FWHM) duration and 1.054 micrometer wavelength. A maximum of 5 joules was used for all shots reported here. (At higher energies, the laser's Qswitch leaked creating a $>0.1 \mathrm{~ms}$ long pulse prior to the Q-switched pulse, which yielded lower flyer velocities and unpredictable results.) The launch laser beam is directed through a lens and diffractive optical element (Mems Optical Inc., Huntsville AL) and finally onto the rear of the substrate window. 
Digital images of the beam at the position of incidence on the substrate were collected and analyzed. (Beamcode, Coherent Laser Inc.) Two cross-sectional views of the beam profile are shown in Figure 1. Just over $80 \%$ of the energy are inside a 3-mm diameter.

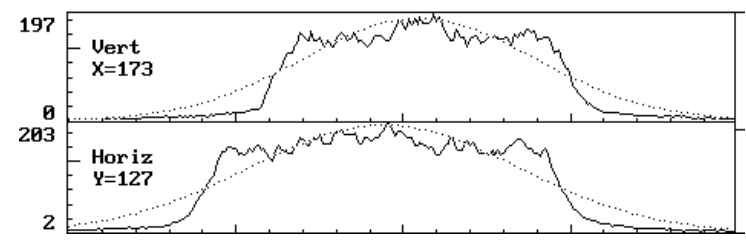

FIGURE 1. Vertical and horizontal cross-sections through the laser beam at the position of incidence on the substrate window. Analysis of the profile indicates approximately $80 \%$ of the beam is within a $3 \mathrm{~mm}$ diameter.

Four different windows were used in this study: 1) sapphire (Saphikon Inc. NH USA, part \# 15959), 2) fused silica, (Heraeus Amersil, part \# 27385), 3) high grade BK-7, (Rocky Mountain Instrument Products, CO USA part \# WI1901K), and 4) low grade BK-7, (Esco Products, NJ USA part \# P907063). The windows were coated with the following sequential layers: 5,000 $\AA$ of carbon, 5,000 $\AA$ of aluminum oxide, and finally with either $5,000 \AA$ or $50,000 \AA$ of aluminum. Copper flyers were purchased in 0.05 mm sheets from Goodfellow (OFHC @ 99.95+\%) and cut into $3 \mathrm{~mm}$ diameter rounds. The flyers were then glued to the substrate windows with the deposited material sandwiched between.

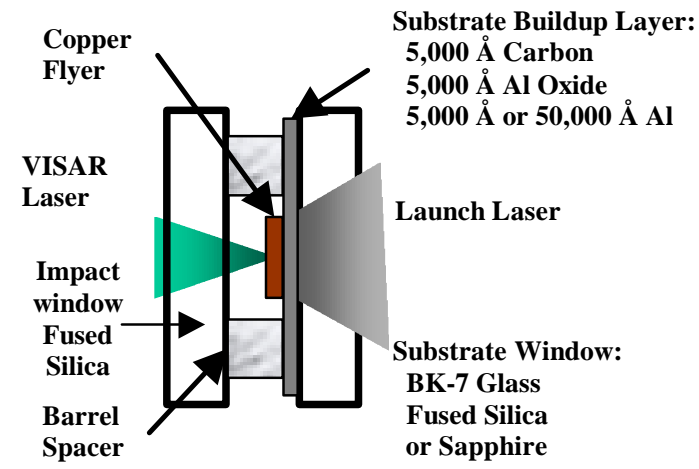

FIGURE 2. Un-scaled schematic of the substrate/flyer assembly prior to firing.
Placing a spacer $(0.125 \mathrm{~mm})$ between the substrate window and the impact window (Figure 2) yielding a total flight path of $0.075 \mathrm{~mm}$ controlled the flight path. All shots were fired in air.

Two velocity interferometers (VISAR), Valyn International (model VLNV-04), were used to record the velocity profiles. A Coherent Verdi laser was used as the VISAR source and was focused to a spot size of approximately $0.1 \mathrm{~mm}$ with 0.1 to $0.2 \mathrm{~W}$ of incident energy.

\section{RESULTS AND DISCUSSION}

A typical measurement of the flyer velocity versus time is shown in Figure 3a. (The result from only one of the two VISARs is shown, since the result determined with the other VISAR agrees with this plot to within $3 \%$.) In this case, the window material is high grade BK-7 and the aluminum coating is $5,000 \AA$ thick. It is seen that the flyer undergoes a rapid initial acceleration, followed by a slower acceleration until impact occurs. The flyer velocity will eventually reach a limit, if it does not impact a target first. There is a small amplitude oscillation on the measured velocity, due to a shock wave propagating in the flyer. To determine the approximate impact velocity of the flyer and the properties of the oscillation, this oscillation must be separated from the data. To accomplish this, the data is fit to a double-exponential curve. The value of the fit at the time of impact is taken as the flyer impact velocity. The difference between the actual data and the fit is then calculated (Figure $3 b$ ) to obtain two pieces of information: the period and the magnitude of the oscillation. The period of oscillation is found to be the same as the round trip time for a sound wave in a 50 micrometer thick copper plate. The amplitude of oscillation for this shot is found to be about $\pm 7.4 \mathrm{~m} / \mathrm{s}$ at the time of impact. This amplitude determines the minimum uncertainty in the velocity at impact.

Figure 4 shows the velocity versus time curves for four different window materials: quartz, sapphire, and low and high grade BK-7. The laser pulse energy is approximately the same for each shot. It is obvious that the initial flyer acceleration is reasonably independent of the window material; the velocity curves begin in almost identical manners. The flyer from the sapphire window does achieve a slightly higher velocity at first, but its velocity levels out earlier and so this flyer achieves a slightly lower impact velocity. Overall, the accelerations and 
impact velocities are too similar to suggest any significant differences due to window material.
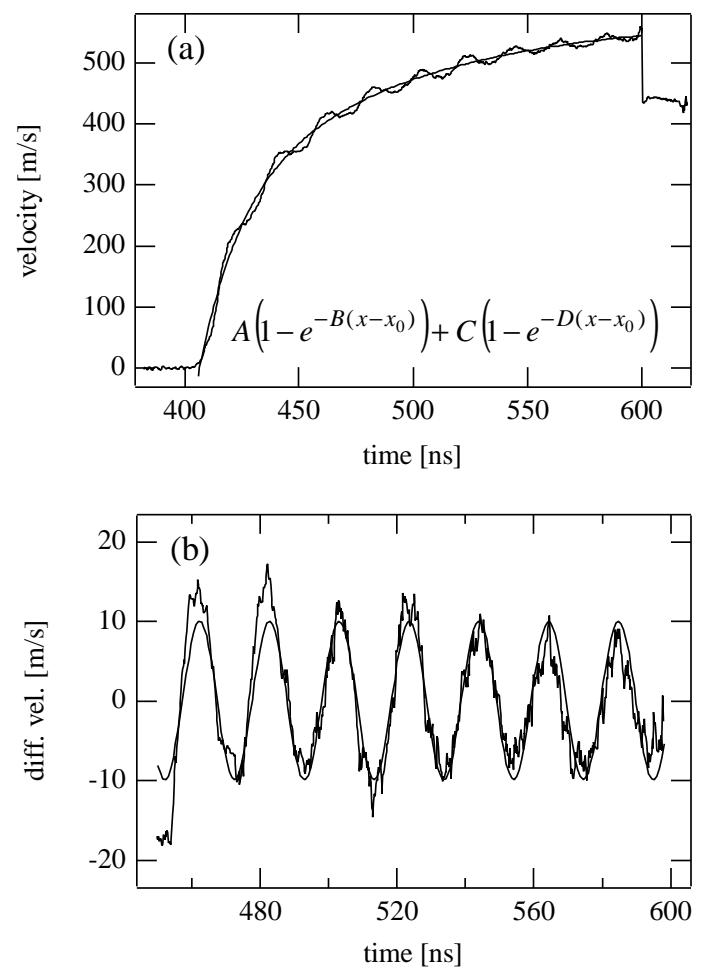

FIGURE 3: a.) Typical flyer velocity versus time profile with double-exponential fit. b.) Difference between velocity data and double-exponential fit, showing oscillation period and amplitude.

However, the amplitude of the oscillations on the velocities appears to be dependent on the window material to a small degree. The amplitude of the oscillations is largest for the sapphire window. This is due to the higher shock impedance of sapphire. The amplitudes of oscillation for the other window materials are lower by approximately $30 \%$. When considering the data for all of the high energy shots ( 5 Joules, $\sim 650 \mathrm{~m} / \mathrm{s}$ ) we find the same qualitative results. Sapphire has the largest average oscillation amplitude at $10.8 \pm 1.6 \mathrm{~m} / \mathrm{s}$, while low grade and high grade BK-7 and quartz have slightly lower average amplitudes at $8.8 \pm 2.5 \mathrm{~m} / \mathrm{s}, 8.7 \pm 1.6 \mathrm{~m} / \mathrm{s}$, and $8.0 \pm 2.6 \mathrm{~m} / \mathrm{s}$, respectively. Thus there is a difference in flyer behavior for the different window materials. However, the difference is sufficiently small to be of no concern in choosing a window material.

The primary goal of our experiments is to determine the effect of window material and substrate thickness on the velocity of the flyer. Figure 5 shows the flyer impact velocity (determined from the double-exponential fits) versus laser pulse energy for

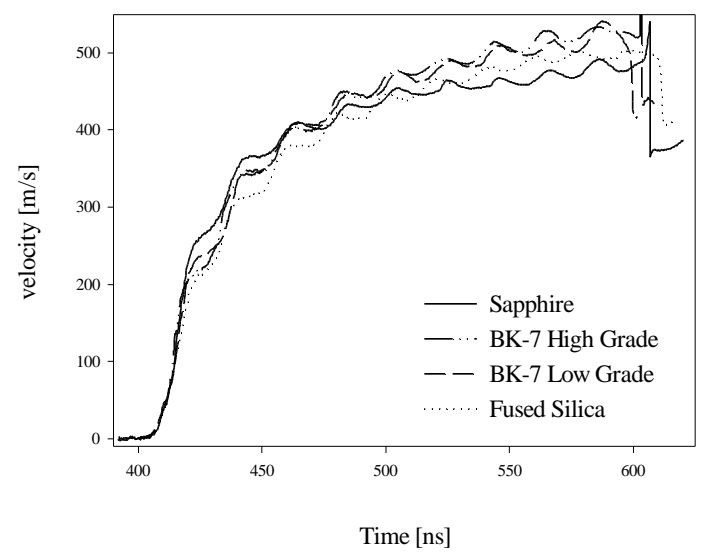

FIGURE 4. Velocity profiles are shown for each substrate window material at a laser energy of 3.3 Joules.

all of the window materials and thicknesses of the aluminum substrate. It is obvious that the points cluster together, with only a ten to twenty percent variation in velocities at a given laser pulse energy. The BK-7 windows tend to yield slightly higher velocities than do the quartz and sapphire windows, but this advantage is small. In addition, there is no definite advantage to using either thick $(5,0000 \AA)$ or thin $(5,000 \AA)$ aluminum coatings. In some shots the thick aluminum yields a higher velocity, in other shots the thin aluminum does. These results are surprising, and may change at higher laser energies.

The highest flyer velocities achieved in our experiments range from 590 to $680 \mathrm{~m} / \mathrm{s}$ using laser pulse energies near 5 Joules. The trend of the data suggests that even higher velocities should be achievable with higher laser energies. We are currently in the process of improving our laser system to reach 10 Joules and hope in the future to achieve up to 20 Joules to search for a limit to the flyer velocities.

The velocity data fit well to a curve of the form $V=V_{0}+A \sqrt{ } E$. This is the expected form, since the kinetic energy of the flyer is proportional to the square of the velocity. The $\mathrm{V}=0$ intercept of the fit occurs at approximately 0.1 Joule, so we predict that the flyers can be launched at very low laser energies.

Based on this fit, the efficiency in converting laser energy into flyer energy may be estimated. The mass of the flyer is approximately 3.15 milligrams. The energy of the laser pulse is adjusted to reflect several losses. Only $80 \%$ of the pulse energy lie within the 3-mm diameter of the flyer. Also, reflections of 
around $4 \%$ of the energy occur at two surfaces on the window between the diffractive optical element and the flyer window and another $4 \%$ reflection occurs at the back surface of the flyer window. Using these adjustments the conversion efficiency is approximately $19 \%$.

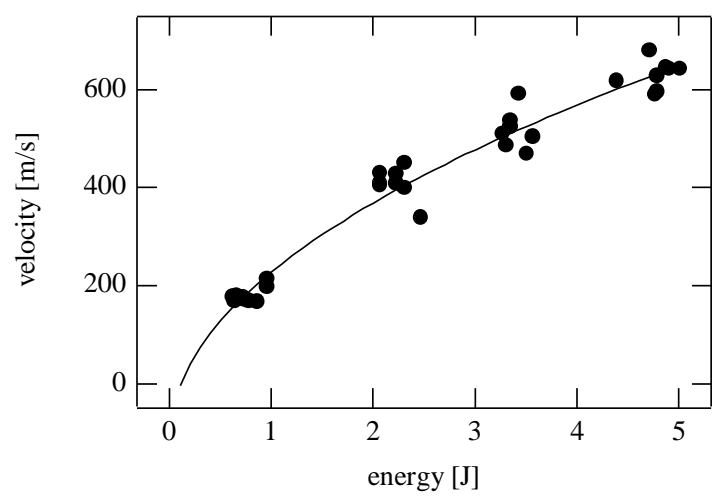

FIGURE 5.: Impact velocity versus laser pulse energy for all of the window materials and both substrate thicknesses.

\section{CONCLUSIONS}

From this data, we conclude that, for the laser energies used thus far, the window material and the aluminum coating thickness are not critical parameters in determining the flyer velocity, which is similar to the conclusions of Sheffield et. al.[3]. Minor differences are apparent: BK-7 windows produce slightly higher flyer velocities (with high grade BK-7 better than low grade BK-7), while quartz windows produce slightly lower magnitude oscillations in flyer velocity. However, these differences are too small to be of serious consideration in choosing our window and substrate materials. This is very advantageous, since it permits us to choose the most cost effective window material and to specify the manufacturing constraints with broad tolerances, thus reducing cost.

In the future we will continue to increase our laser pulse energies to achieve higher velocities and to search for any limitations. One possible concern is that, at higher energies, absorption by the window could have an effect. However, for BK-7 the internal transmittance of a $1 \mathrm{~mm}$ thick sample at a wavelength of $1.054 \mu \mathrm{m}$ is $99.985 \%$ [8]. Hence, a 20 Joule laser pulse would only deposit 3.0 milliJoules in the window, which should not damage the window and therefore should have negligible effect. Based on these observations, we are optimistic that we can achieve significantly higher flyer velocities (in the 1.0 to $1.5 \mathrm{~km} / \mathrm{s}$ range for a $0.05-\mathrm{mm}$ OFHC flyer) with this method.

\section{ACKNOWLEDGMENTS}

The authors appreciate the support and equipment supplied by Willard Hemsing (Los Alamos Nat. Lab.) for data acquisition/analysis. We also acknowledge Bryan Adams, Bill Price, and Ben Rosenblum from AlliedSignal/FM\&T Kansas City Plant for work on substrate deposition and flyer/substrate assembly. This work was supported by the DOE Enhanced Surveillance Program through contract DE-AC04-76DP00613.

\section{REFERENCES}

1. Moshe, E., Dekel, E., Henis, Z., Eliezer, S., Appl. Phys. Lett. 69, 1379-1381 (1996).

2. Dekel, E., Eliezer, S., Henis, Z. Moshe, E., Ludmirsky, A., and Goldberg, I. B., J. Appl Phys. 84, 4851-4858 (1998).

3. Sheffield, S. A., Rogers, J. W. Jr, and Castaneda, J. N., "Velocity Measurements of Laser-Driven Flyers Backed by High Impedance Windows," in Shock Waves in Condensed Matter-1985, edited by Y. M. Gupta, Plenum Press, New York, 1986, pp. 541-546.

4. Romain, J. P, Cottet, F., Hallouin, M., Fabbro, R., Faral, B., and Pepin, H., Physica B \& C 139 \& 140B, 595-598 (1985).

5. Youtsos, A. G., Kiriakopoulos, M., and Timke, Th., Theoretical and Applied Fracture Mechanics 31, 47-59 (1999).

6. Warnes, R. H., Paisley, D. L., and Tonks, D. L., "Hugoniot and Spall Data from the Laser-Driven Miniflyer," in Shock Compression of Condensed Matter-1995, edited by S. C. Schmidt and W. C. Tao, AIP Conference Proceedings 370, New York, 1995, pp. 495-498, 495-498, Seattle, WA, August 13-18, 1995.

7. Paisley, D. L., "Laser-Driven Minature Plates for One-Dimensional Impacts at $0.5-\geq 6 \mathrm{~km} / \mathrm{s}$ " in Shock-Wave and High-Strin-Rate Phenomena in Materials, edited by M. A. Meyers, L. E. Murr, and K. P. Staudhammer, Marcel Dekker, Inc., New York 1992, pp. 1131-1141.

8. Melles Griot, Optics Guide 4, pp. 3-7 (1988) 